\title{
Credit Unions and the Supply of Insurance to Low Income Households
}

by

\section{Pat McGregor" and Donal McKillop**}

\footnotetext{
*Pat McGregor, Department of Economics, University of Ulster, Newtownabbey, Jordanstown, Northern Ireland.

e-mail ppl.mcgregor@ulst.ac.uk

** Donal McKillop, Professor of Financial Services, School of Management and Economics, Queens University Belfast, University Road, Belfast, Northern Ireland. e-mail dg.mckillop@qub.ac.uk

The authors are indebted to Dave Canning (Harvard) and Michael Moore (Queens) for their comments on an earlier version of the paper though responsibility for any remaining errors are the authors.
} 


\section{Credit Unions and the Supply of Insurance to Low Income Households}

\section{Section 1 Introduction}

One aspect of the vicious circle of poverty in distressed neighbourhoods is the paucity of institutions such as commercial banks that provide credit there (see for example, Flowers (1999) and Dymski and Mohanty (1999)). Given their characteristics, it would be anticipated that credit unions should have a natural role to play in such circumstances. ${ }^{1}$ In fact some credit unions are specifically designated as 'low-income' and are chartered to serve those of modest means. ${ }^{2}$

The central focus of this paper is to develop a behavioural model for lowincome credit unions where the credit union operates as a financial intermediary providing both a credit service and an insurance service to low-income members. In particular, the credit union enables the low-income household to trade, in an uncertain environment, intertemporal claims for financial services and thus engage in consumption smoothing. ${ }^{3}$ The model is built upon two premises derived from the environment within which low-income credit unions operate. First, all members must make a deposit prior to being admitted to the credit union. The deposit is similar to an insurance premium but one where the return is in the form of an interest payment if the member's income is normal but if income is unfavourable the member has the right to credit. Second, low-income credit unions have a well-defined common bond

\footnotetext{
${ }^{1}$ The US Treasury (1997) documents five characteristics, which distinguish credit unions from other financial forms. One of these characteristics is that credit unions are charged with providing basic financial services to individuals of modest means.

${ }^{2}$ The National Credit Union Administration (NCUA) defines a low-income credit union as one in which a majority of members earn either less than 80 percent of the average for wage earners (as defined by the Bureau of Labour Statistics) or whose annual household income falls below 80 percent of the median household income for the nation.

${ }^{3}$ Exclusion from such institutions does not imply that insurance is impossible - in developing countries a considerable level of consumption smoothing occurs despite limited financial infrastructure. This is achieved by informal arrangements and the development of innovative approaches to deal with informational asymmetries (see the symposium contained in the Journal of Economic Perspectives, Summer, 1995, especially the paper by Morduch.
} 
that results in greater information flows to the management of the credit union. Building upon these premises the argument is developed that the low-income credit union is an institution with a particular contract that is designed to operate in a region (defined in terms of the credit union member's expected income) that commercial banks exclude themselves from because of the impact of informational asymmetries on their contract.

The model highlights several potential constraints that credit unions operate under and the empirical section investigates their prevalence. Low-income credit unions are classified into four categories on this basis with the important conclusion that only a minority of even 'low-income' credit unions operate in environments where their activities will make a significant contribution to the economic welfare of the locality.

In terms of the paper's format the following sectionalised approached is adopted. Section 2 concentrates upon establishing the model and emphasises why commercial banks do not cover the low-income section of the market. The demand for loans is stimulated by a negative income shock. A central feature of the model is the incorporation of a guaranteed level of income that can be accepted as an alternative to a negative income shock. The primary characteristic of the credit union contract is that it is entered into before the result of the current income draw is known (members must make a deposit prior to being admitted to the credit union). This entitles the lowincome member to a loan that will only be taken up if a negative income shock occurs. The analysis demonstrates that the challenge facing the credit union is to distinguish between those low-income members on the minimum income guarantee who want to smooth consumption in the expectation of a positive income shock in the 
next period and those who seek the largest loan possible with the intention of defaulting.

Section 3 provides a brief overview of those low-income credit unions currently operating in the US. The data set considered is a panel of 666 low-income credit unions with observations available on a semi-annual basis over the period 1990 to 2000. Section 4 presents the empirical evidence. A contingency table format is adopted that enables the analysis to determine the differing motivations and modus operandi between the four identified sub-groups within low-income credit unions. Section 5 completes the discussion with a number of concluding comments.

\section{Section 2 The Model}

\section{The demand for loans from commercial banks}

Agents maximise expected utility, $U$, over two periods, in each of which income is a random variable of the Bernoulli type with mean $x$. The outcome $N$, (where the agent experiences a negative shock) is associated with an income of $x-\frac{m}{\alpha}=x_{N}$ which occurs with probability of $\alpha$. Similarly the outcome $P$, (where the agent experiences a positive shock) is associated with an income of $x+\frac{m}{1-\alpha}=x_{P}$ which occurs with probability $1-\alpha{ }^{4}$ The agent discounts future income at the rate $\delta$. A commercial bank that advances a loan $L$ in the current period will demand a payment of $r L$ in the next period.

The model developed in this paper concentrates wholly on the question of loans and thus on the situation when $N$ occurs. If $P$ occurs then consumption

\footnotetext{
${ }^{4}$ This construction allows a negative shock to be greater in magnitude than a positive one if $\alpha<0.5$. This provides a more realistic modelling of the impact of unemployment on income.
} 
smoothing will entail saving. However, this can be accommodated straightforwardly by either commercial banks or credit unions. The essential distinction between the two institutions in this paper is on the loan side and for clarity the deposit side is ignored. The demand for loans is only positive when $N$ occurs and its magnitude, $L$, is determined by a simple optimisation exercise:

$$
\underset{L}{\operatorname{Max}} E[U \mid N]=U\left(x_{N}+L\right)+\alpha \delta U\left(x_{N}-r L\right)+(1-\alpha) \delta U\left(x_{P}-r L\right) .
$$

The first order conditions are not particularly informative. The result is much more illuminating if its generality is reduced by assuming the nature of risk aversion. Consequently constant absolute risk aversion (CARA) is assumed and the utility function $-e^{-a x}$ is employed. The optimal loan, $L^{*}$, is then

$$
L^{*}=\frac{1}{a(1+r)}\left[\frac{a m}{\alpha}-\ln r \delta d\right]
$$

where $d=\alpha e^{a m / \alpha}+(1-\alpha) e^{-a m / 1-\alpha}$. There are a number of aspects of this solution which deserve to be highlighted. First, the magnitude of $L^{*}$ is independent of mean income, $x$. This reflects in part that $m$ is taken as constant rather than $m(x)$. This impairs the realism of the model but ths is outweighed by the gain in tractability. Second, if $\frac{a m}{\alpha} \leq \ln r \delta d$ then the agent is better off having no loan at all. The utility in such a case will be referred to as $U_{0}$ and will achieved at some point as $r$ is continuously increased. The third and most important aspect of (2) is that from the bank's viewpoint, if $L^{*}>0$ then the probability of default is zero. This severely limits the model's plausibility if income is low.

Default is introduced by assuming that all agents, as an alternative to accepting their income draw, are entitled to an exogenously determined level of 
income, $b$, referred to as the Minimum Income Guarantee (MIG). ${ }^{5}$ When, for example, the negative income shock is associated with being made redundant $b$ would be the level of unemployment insurance payments. Thus default will occur whenever $x_{N}-r L \leq b$. In such circumstances and provided that $x_{P}-r L>b$ then the expected utility will be given by:

$$
E\left[U_{b} \mid N\right]=U\left(x_{N}+L_{b} *\right)+\alpha \delta U(b)+(1-\alpha) \delta U\left(x_{P}-r L_{b} *\right)
$$

where $L_{b}^{*}=\frac{1}{a(1+r)}\left[\frac{a m}{\alpha(1-\alpha)}-\ln (1-\alpha) \delta r\right]>L^{*}$ for the CARA case. Now $L_{b} *$ is still independent of $x$ but as long as $x<x^{*}$, where $E[U(x *) \mid N]=E\left[U_{b}\left(x^{*}\right) \mid N\right]$ then the probability of default is $\alpha$. The introduction of the default option makes the model more plausible but $L_{b} *$ is still independent of mean income.

This independence does not hold when the agent seeking the loan is currently receiving the MIG. In such circumstances the agent will inevitably default on the loan if $N$ occurs in the next period. As long as $x_{P}-r L>b$ then the expected utility will be given by:

$$
E\left[U_{b b} \mid N\right]=U\left(b+L_{b b} *\right)+\alpha \delta U(b)+(1-\alpha) \delta U\left(x_{P}-r L_{b b} *\right)
$$

where $L_{b b} *=\frac{1}{a(1+r)}\left[a\left(x_{P}-b\right)-\ln (1-\alpha) \delta r\right]$ for the CARA case. The optimal loan is now an (increasing) function of $x$. When $x=b+m / \alpha$ that is $x_{N}=b$ then $L_{b} *=L_{b b}{ }^{*}$ and the expected utilities under equations (3) and (4) are the same; this point gives the switch over between the two loan demand schedules.

\footnotetext{
${ }^{5}$ The model developed above is in several respects the mirror opposite to that of Parlour and Rajan (2001). They have lenders offering different contracts to a single borrower who considers default strategically, based on the degree of leniency in the bankruptcy laws. This performs a role similar to that of the MIG in this paper where default is generally triggered by a negative income shock, except in the case of the intentional defaulter whose calculation is strategic.
} 
The demand for loans is sketched in Fig 1. It is the declining portion of the curve that is of central interest in explaining the role of the credit union. The first point to highlight is the level of income, $x^{* *}$, below which default occurs with certainty, that is, when $x * *+\frac{m}{1-\alpha}-r L_{b b}=b$. The condition $(1-\alpha) \delta r<1$ ensures that at $x * *$ the demand for loans is positive, that is, $L_{b b}>0$.

Below $x^{* *}$ the agent has no intention of repaying the loan (he is an intentional defaulter, ID); essentially a loan of infinite size would maximise his utility if the problem is expressed as a simple modification of (4). At this point it is necessary to consider the position from the bank's perspective and to include this into the optimal strategy for the defaulter.

Assume that the bank cannot observe $x$ and that its information is limited to the size of loan being demanded by an agent. For example, if $L_{b} *$ is sought then the bank would surmise that either $b+m / \alpha \leq x \leq x^{*}$ or possibly that $x<x^{* *}$ (see Fig. 1). Provided that the cost of funds is less than $(1-\alpha) r$ then the bank will be making an expected profit on those whose income lies between $b+m / \alpha$ and $x *$. If an agent sought a loan in excess of $L_{b} *$ the bank would be alerted to his intention to default. This would be recognised by the agent and hence $L b^{*}$ is the largest loan sought, as indicated in Fig 1.

There are four regions in the demand curve for loans, determined by the role of $b$. For $x>x^{*}$ there is no default and $L^{*}$ is employed purely for consumption smoothing. When $x^{*}>x>b+m / \alpha$ and the agent is employed in the current period, default occurs with $N$ in the second period. For $b+m / \alpha>x>x^{* *}$ the agent is receiving the minimum income guarantee in the current period but will repay the loan if $P$ occurs in the following period. If $x<x^{* *}$ then the agent is on the minimum 
income guarantee and is seeking the largest loan that he believes the bank could be induced to lend him. In the latter case the agent has no intention of repaying irrespective of the outcome of the income draw.

If it is assumed for clarity that each institution can only offer one form of contract then the result is straightforward: the bank will not lend to anyone who is currently on the MIG if there are a substantial number for whom $x<x^{* *}$. The loans market exhibits informational asymmetries similar to that modelled by Akerlof (1970). Those who demand $L_{b} *$ are made up of the consumption smoothers who will only default with $N$ and the 'lemons' who have no intention of repaying. The bank cannot distinguish between them.

\section{The contract offered by the credit union}

The primary characteristic of the credit union contract is that it is entered into before the result of the current income draw is known and so unlike the bank contract the model becomes a three period one similar to that of Diamond and Dybvig (1983). In the first period the agent must decide whether or not to join the credit union. This is before the result of the first income draw is known which now occurs in period two. In the third period the decision on whether or not to repay the loan is taken and so is formally identical to the bank loan model.

The motivation underlying the credit union contract is the exclusion of the intentional defaulter. This is achieved by specifying a deposit, $c$, which must be lodged by all credit union members. The deposit of $c$ imposes a cost on agents. It is assumed that the tightly defined common bond of credit unions give them an informational advantage over banks in that they are aware of whether $N$ or $P$ has occurred for the agent. This impacts on the intentional defaulter since it excludes him from applying for a loan when $P$ occurs and yet the intentional defaulter will still be 
required to reduce current consumption then by $c$. The intentional defaulter is characterised by a relatively low income and consequently the level of $c$ can be adjusted such that its cost ensures that it is not rational for the intentional defaulter to become a member of the credit union.

The deposit of $c$ entitles the agent to a loan, $l$, which will only be taken up if $N$ occurs. The contract specifies the rate, $s$, that will be charged, so that $s l$ is agreed to be repaid in the next period. Irrespective of whether a loan is taken out, $c t$ is repaid to the agent in the next period. In the case of the bank, saving was ignored as a form of consumption smoothing. To be consistent in the credit union case, the deposit of $c$ when $P$ occurs must have a net negative effect on utility; $t$ must not be so large that it gives an incentive to save.

The argument developed in this paper is that the credit union is an institution with a particular contract that is designed to operate in a region that banks exclude themselves from because of the impact of informational asymmetries on their contract. Consequently the institutions operate in different areas of the demand for loans curve. Banks deal with agents for whom $x>b+m / \alpha$ while the credit unions offer contracts to those for whom $x<b+m / \alpha$ such that the intentional defaulter is screened out.

Credit unions thus deal with those on the minimum income guarantee; the challenge facing them is to distinguish between those whose motivation is consumption smoothing and those who seek the largest credible loan with the intention of defaulting. In the former case the expected utility from joining a credit union is:

$$
\begin{aligned}
E\left[U_{c u}\right]=\quad & \alpha U\left(b-c+l_{b b}\right)+\alpha \delta U(b)+\alpha(1-\alpha) \delta U\left(x_{P}+c t-s l_{b b}\right) \\
+ & (1-\alpha) U\left(x_{P}-c\right)+(1-\alpha)^{2} \delta U\left(x_{P}+c t\right)
\end{aligned}
$$


If the result of the income draw in the second period is negative then the agent will be in receipt of the minimum income guarantee and desires to increase consumption then on the expectation of a positive income draw in period three (a negative income draw in this period will result in default). Thus, unlike the bank case, the decision to join the credit union will have an impact on utility when $P$ occurs. The first order condition for optimal loan size is:

$$
U_{b-c+l_{b b}}^{\prime}=(1-\alpha) \delta U_{x_{P}+c t-s l_{b b}}^{\prime}
$$

and reflects the possibility of default in the third period; if repayment had been anticipated then the right hand side would include another term, reducing $l$. In the CARA case $l_{b b}=\frac{1}{a(1+s)}\left[x_{P}+a c(1+t)-a b-\ln (1-\alpha) \delta s\right]$.

A clearer picture of the operation of the credit union is gained from dividing the expected utility from membership into two parts, depending on the result of the income draw in period two. The expected utility from not joining the credit union is given by $E\left[U_{0 b}\right]=(1+\delta)\left[\alpha U(b)+(1-\alpha) U\left(x_{P}\right)\right]$ and so the gain, $G$, from membership is defined as $G=E\left[U_{c u} \mid N\right]-E\left[U_{o b} \mid N\right]$. In the CARA case this becomes, with the incorporation of the first order conditions:

$$
G=-\left(\frac{1+s}{s}\right) e^{-a\left(b-c+l_{b b}\right)}+e^{-a b}+(1-\alpha) \delta e^{-a x_{P}}
$$

$G$ is increasing in $x$ and $t$ and decreasing in $c$ and $s . G(c=0, s=1)>0$ so for some parameter values membership given $N$ is beneficial. The cost of membership, $C$, is apparent when $P$ occurs. $C=E\left[U_{o b} \mid P\right]-E\left[U_{c u} \mid P\right]>O$ where the sign follows from the assumption that $t$ cannot be so large that the deposit of $c$ becomes an efficient 
saving device for consumption smoothing $(t \delta<1$ is a sufficient and reasonable condition to ensure this). $C$ is then decreasing in $x$ and $t$ but increasing in $c$.

$G$ and $C$ are graphed against $x$ in Fig 2. If $c=0$ then the situation is identical to that involving a bank $-C(c=0)$ is superimposed on the horizontal axis. Then providing $G>0$ all income levels will join the credit union. The range of $x$ being considered is between that for which $l_{b b}>0$ and $b+m / \alpha$. The intersection between $G$ and $C$, at $x_{L}$, gives the lowest income level for which it is rational for an agent to join the credit union. The existence of this limit is due to the deposit requirement $c$. An increase in $c$ shifts $C$ upward and $G$ downward, thus leading to an increase in $x_{L}$. Such a result can also be engineered by the credit union by increasing $s$ or reducing $t$. The particular value of $x_{L}$ that it chooses and the manner in which it achieves it will depend upon its objective function and is examined below.

\section{The credit union and the intentional defaulter (ID)}

The presence of the intentional defaulter who took on a loan with no intention of repaying it was the cause of the bank withdrawing from the loans market for those agents with $x<b+m / \alpha$. How does the credit union contract perform in this situation? Like all members the intentional defaulter will be required to pay $c$ to be admitted to the credit union. Although the credit union, like the bank, does not observe $x$ it does observe whether $N$ or $P$ has occurred. This may be taken as a reflection of the greater information available to the managers in the credit union due to the nature of the common bond.

In the context of this model the minimum income guarantee, $b$, is assumed means tested so the deposit plus interest is effectively lost in the third period when default occurs. The choice in relation to joining the credit union will be based on a comparison between the utility derived from being an intentional defaulter and that of 
being poor. The latter alternative consists of receiving $b$ on all occasions and thus yields $E\left[U_{P}\right]=(1+\delta) U(b)$. Now the intentional defaulter will derive the same utility in the third period as the poor agent; the comparison between the two alternatives thus hinges on the second period. The loan sought by the intentional defaulter is the largest that a bone fide member would seek. This will be the loan, $l_{b b}^{\max }$ sought by the agent on the highest income in the credit union, namely $b+m / \alpha$.

Thus for the credit union contract to screen out the intentional defaulter it is necessary that:

$$
E\left[U_{I D}\right] \leq E\left[U_{P}\right] \Leftrightarrow \alpha U\left(b-c+l_{b b}^{\max }\right)+(1-\alpha) U(b-c) \leq U(b) .
$$

This is illustrated graphically in Fig 3. The smaller $\alpha$, the probability of the negative income shock, is then the expected utility of the intentional defaulter will be closer to $\mathrm{A}$ on the chord $\mathrm{AB}$ and so the more likely condition (8) is met. If $b$ is small then the slope of the utility function may be quite steep at this point and the fall to $U(b-c)$ might be large, making the achievement of the screening condition more likely. The central point is that $c$ is the basis of the credit union contract lever on screening. For the CARA case condition (8) reduces to

$$
\alpha e^{-\frac{1}{1+s}\left[\frac{a m}{\alpha(1-\alpha)}-a c(s-t)-\ln (1-\alpha) \delta s\right]}+(1-\alpha) e^{a c} \geq 1 .
$$

The left hand side of (9) is increasing in $c$.

Condition (8) allows the construction of a function, $g(c, s, t)=0$, of which (9) when an equality is an example, which restricts the set of decision variables in the credit union contract so that the intentional defaulter is indifferent to joining the credit union. The probability of default for those that remain is thus $\alpha$. 


\section{The membership of the credit union}

The exclusion of the intentional defaulter will also have the effect of excluding some of the poor from joining the credit union. For example, if $c$ was marginally reduced then it would become rational for those whose income is close to $x_{L}$ (see Fig. 2) to join the credit union. Such agents would not be intentional defaulters; their default would be triggered by $N$ occurring in period three. Thus establishing a disincentive for the intentional defaulter has the effect of depriving some agents on low incomes from gaining a potential welfare improvement. Thus the credit union contract cannot be Pareto optimal. Let $E\left[U_{I}\right]=(1+\delta)\left[\alpha U(b)+(1-\alpha) U\left(x_{P}\right)\right]$ be the utility of an agent who decides to be independent of the credit union. Then the agent with lowest income, $x_{L}$, in the credit union will be indifferent between membership and independence, that is, $E\left[U_{I}\left(x_{L}\right)\right]=E\left[U_{c u}\left(x_{L}\right)\right] . x_{L}$ will, of course, be a function of the decision variables of the credit union so that $x_{L}=x_{L}(c, s, t)$.

\section{The operation of the credit union}

The first issue to be tackled in a model of the credit union is the nature of the objective function. Members include both borrowers and savers: one strand in the theoretical literature takes the interest of one of these groups as paramount and considers the objective function to be either the maximisation of interest income of savers or the minimisation of the rate of interest to borrowers (see, for example, Overstreet and Rubin,1990; Smith 1984, 1986; and Srinivasan and King, 1998). Such an approach ignores two central features of the institution. The first of these is the social welfare motivation associated with the development of credit unions. They are a classic example of the self help philosophy applied to low income households as evidenced by many unions relying on volunteers to run the organisation. 
The second feature is that the division between savers and borrowers is a false dichotomy. Insurance and credit motives are in reality combined; the deposit required for membership is similar to an insurance premium but one where the return is interest if the agent's income is normal but if unfavourable the agent has the right to credit. ${ }^{6}$ Which aspect is dominant to any agent depends on the outcome of a random process; they constitute two sides of the same coin. To exclude one in defining the objective function of the credit union thus risks ignoring a central characteristic of the institution.

The motivation of the credit union is taken to be the maximisation of the consumer surplus on loans, $L$, to its membership that is of size $M$. The consumer surplus is $C S=\int_{s}^{\infty} L(s, t, c) d s$; only the contribution of loans is considered because of their role in insurance. Loans have to be funded so the credit union will be required to balance its loans by deposits from members, $c M$. In the third period the loans actually repaid by members, $s(1-\alpha) L$ will offset the deposits that the credit union has to return to members, $t(1-\alpha) c M$.

In addition to the accounting constraints, it is possible that the constraint to exclude the intentional defaulter will be operative. There are two situations that would exclude its operation. The first is if the optimal conditions for $c, s$ and $t$ mean that condition (8) is satisfied as a strict inequality. The second is that the number of intentional defaulters is relatively small and their defaults can be covered by the surplus generated by the spread of $s$ over $t$. Thus it is anticipated that the default rate is positively related to the interest rate spread.

The optimisation problem facing the credit union is then:

\footnotetext{
${ }^{6}$ Such linkage of credit and insurance is also evident in the development literature - see Basu, (1997).
} 


$$
\begin{aligned}
& \underset{c}{\operatorname{Max}, t} \operatorname{CS} \\
& \text { Subject to } L=c M \\
& E\left[U_{I D}\right] \leq E\left[U_{P}\right]
\end{aligned}
$$

The conditions for the optimal choice of $c, s$ and $t$ can be presented more clearly if income is assumed to be continuously distributed with density $f(x) .^{7}$ Defining the elasticities, $\eta_{y}^{X}=\frac{\partial X}{\partial y} \frac{y}{X}$ means that the optimal condition, if the informational constraint, condition (8), does not bite, can be expressed as:

$$
\eta_{s}^{L}=\eta_{s}^{M}
$$

Should condition (8) hold then there are a series of additional terms in equation (11) that it is not possible to sign.

The credit union operates in a three period framework; the agent's decision to join is taken in the first period having considered the levels of $c, s$ and $t$. The solution to (10) ensures that the accounting constraint is satisfied in the second period when the results of the income draw are revealed. Consequently $s>t$ will imply that there is a surplus in the third period. This is optimal because, for example, reducing the loan rate will stimulate the demand for loans which will require the generation of additional deposits by altering the other decision variables. The result would then violate the first order conditions for (10).

However, if a credit union anticipated a surplus in the third period it would consider borrowing funds, $R$, from the market in the second and adjust its decision variables such that its surplus in the third period was equal to $\rho R$, where $\rho$ is the market return on funds. The impact can be clearly seen by considering it in two

\footnotetext{
${ }^{7}$ Then aggregate loans, $L$, will be: $L=\int_{x_{L}}^{x_{U}} l_{b b} \alpha f(x) d x$ and membership, $M=\int_{x_{L}}^{x_{U}} f(x) d x$.
} 
stages. First, et $R$ be a cash endowment of the credit union so the funding constraint becomes $L=c M+R$. The equilibrium condition then becomes:

$$
(1+R / L) \eta_{s}^{L}=\eta_{s}^{M}
$$

Clearly, the larger $R$ is, the more likely that (12) will be rejected.

Next consider the case when $R$ is borrowed. This necessitates the introduction of a second multiplier, $\lambda_{2}$, upon the second period constraint, $(1-\alpha)(L s-c M t)-\rho R$, into the Langrangian function of the problem, (10). Three points should be noted. First, it is assumed that both constraints bite which is reasonable given that in the solution to (10) the multiplier is:

$$
\lambda_{1}=\frac{-\frac{t}{L} \frac{\partial C S}{\partial t}}{\eta_{t}^{M}-\eta_{t}^{L}}=\frac{-\frac{c}{L} \frac{\partial C S}{\partial c}}{1+\eta_{c}^{M}-\eta_{c}^{L}}
$$

It would be anticipated that $\lambda_{I}>0$ and that borrowing would occur for as long as $\lambda_{I}>$ p. Now $\lambda_{2}=0$ would imply that there was a surplus in the second period and so $C S$ could be increased by raising $R$. The second point is that, given this, $\rho=\lambda_{1} / \lambda_{2}$. The credit union will take $\rho$ as given so it is likely that the optimum for some unions will be not to enter the market for funds and to accept the presence of surplus funds in the third period. Clearly, if $\rho$ is continuously increased, such an outcome will eventually occur for all unions. The final point is that restriction (12) is changed to:

$$
\frac{1}{1-\frac{\rho}{s(1-\alpha)}}+\eta_{s}^{L}=\eta_{s}^{M}
$$

In summary, the elasticity constraint given by equation (11) will be violated either by the operation of the intentional defaulter constraint (8) or alternatively by the credit union becoming active in the funds market. 
What does the model have to say about the central issue of this paper, the potential role of credit unions in the provision of financial services in distressed neighbourhoods?

1. The higher the level of $\alpha$, the probability of a negative income shock, the more difficult it is to screen out the intentional defaulter, as shown in Fig. 3. Without the operation of this constraint, both the minimum deposit, $c$, and the loan rate, $s$, could be lower, so its operation reduces the potential contribution of credit unions to distressed neighbourhoods.

2. The operation of the intentional defaulter constraint is not automatic. If the equilibrium levels of $c$ and $s$ are high then the lowest income level that it is rational to be a member of the credit union, $x_{L}$, will also be high so again the potential benefit to those with the lowest incomes is removed.

3. If the number of potential intentional defaulters is low, then, provided the spread between the loan and the savings rate is sufficiently large, then it may be optimal for the credit union not to alter its decision variables but instead to accept the higher default rate. But the proportion of intentional defaulters reflects not only the levels of decision variables but also the incidence of distress in the neighbourhood; again, it would be anticipated that credit unions in distressed neighbourhoods would operate under the intentional defaulter constraint.

4. The operation of the intentional defaulter constraint is seen in the violation of the condition $\eta_{s}^{L}=\eta_{s}^{M}$. This does not identify the operation of the constraint since such a violation can also result from substantial borrowings from the funds market. In the latter case the credit union would be generating a surplus that would not be anticipated from a distressed neighbourhood. 
5. The operation of the intentional defaulter constraint would be anticipated to reduce the rate of growth of the credit union since decision variables would be set at levels above institutions in more favourable environments. Again, this constrains the potential contribution of credit unions to relieve economic distress.

\section{Section 3 The Data}

Low-income credit unions, like other credit unions are: democratically controlled; not-for-profit; insured; government-regulated; and operated by volunteer boards of directors. What sets these credit unions apart is their special mission of serving low-income communities. Federal law and regulations endorse this mission by giving such credit unions the privilege of raising deposits and capital from nonmembers. Low-income credit unions often need third-party deposits, low-interest loans and technical assistance to enable them to grow and stabilise their operations. Only credit unions that are designated as low income have the authority to accept nonmember deposits, the most likely source of which are the larger credit unions, banks seeking Community Reinvestment Act credit, local businesses and foundations.

The National Credit Union Administration Board (NCUA) created the Office of Community Development Credit Unions in early 1994 to provide counselling to low-income credit unions and to administer the agency's Community Development Revolving Loan Program (CDRLP). To qualify for the below market-rate loans and free technical assistance grants provided through the CDRLP, community development credit unions must apply and receive the special "low-income" designation. The heart of the NCUA's effort to assist low-income credit unions is through the Revolving Loan Program. Under the agency's stewardship since 1987, the

CDRLP's original \$6 million appropriation has been revolved into $\$ 13$ million in loans. 
Some low-income credit unions offer basic services one or two days a week in church halls. Others have modern, full-service facilities, complete with ATMs. All low-income credit unions offer small personal loans. Some provide larger loans for housing, agriculture, small and minority businesses, and nonprofit organizations. Tansey (2001) argues that at the end of the 1990s low-income credit unions had $\$ 6$ billion in assets with a capital ratio of 12.1 percent (the average capital ratio for all credit unions was 11 percent). Their loan portfolio was made up of: used autos 24 percent, first mortgages 22 percent, new autos 16 percent, unsecured loans 10 percent, other real assets 6 percent and credit cards 5 percent. Not withstanding the higher risk profiles of their constituencies, low-income credit unions ran only a marginally higher delinquency and charge-off rate than the credit union sector as a whole (Tansey, op. cit.).

Callaghan Associates have provided the data employed in this study. It is presented on a semi-annual basis and covers twenty observations in the period from June 1990 to December 1999. There are 704 credit unions designated as low-income. Of this number complete and usable data for the entire period was available for 666 cases.

\section{Section 4 Empirical Analysis}

This section seeks to identify those credit unions where the intentional defaulter constraint operates and to analyse its consequences. The maximisation of the consumer surplus on loans represented in (10) produces one testable restriction, namely $\eta_{s}^{L}=\eta_{s}^{M}$, (11), provided that the intentional defaulter constraint does not bite and activities in the funds market are minor. If the latter does not hold, there are two potential consequences. First, the accounting constraint in (10), $L=c M$, is changed to $L=c M+R$ which implies that (11) is changed to (12) and so the former is quite 
likely to be rejected. Second, changes in $\rho$ are likely to affect $s$. Thus credit unions where the intentional defaulter constraint bites can be identified by violation of (11) together with the levels of decision variables not being affected by the rate on funds. Such a linkage would also follow from competitive pressures from commercial banks (Feinberg (2001)).

The contract that the credit union sells is in essence an insurance one and changes in the price of loans from commercial banks have no impact since the membership of the credit union are by assumption excluded from commercial banks. The first order conditions of the optimisation problem, (10), contains integrals of the derivatives of $L$, total loans. The economic impact of the credit union's neighbourhood is thus seen through the effect on the demand for loans. While an increase in the unemployment rate or a fall in personal income will increase the demand for loans, an increase in the rate of interest in itself should generally have no effect.

The degree of integration of the credit union with financial markets is tested by regressing the logs of the decision variables, $d_{j}$, upon the variables, $Y$, namely state average personal income per worker, INC, the price level, PRICE, and the unemployment rate, $U$, and the current and lagged values of the federal funds rate, fed:

$$
d_{j}=\alpha Y+\beta_{0} f e d_{t}+\beta_{l} f e d_{t-1}+\beta_{2} f e d_{t-2}+\varepsilon
$$

Then the test is simply that of $\beta_{0}=\beta_{1}=\beta_{2}=0$.

To test the equality constraint on the elasticities, equation (11), requires estimating them from running two regressions of the logs of membership and 
aggregate loans on the logs of the decision variables, $c, s$ and $t$, the variables, $Y$, and a dummy variable, $X$, that represents the half year to which the observation pertains.

$$
\begin{aligned}
& \ln M=\alpha_{1} \ln s+\alpha_{2} \ln c+\alpha_{3} \ln t+\alpha_{4} X+\alpha_{5} \ln Y+\varepsilon \\
& \ln L=\beta_{1} \ln s+\beta_{2} \ln c+\beta_{3} \ln t+\beta_{4} X+\beta_{5} \ln Y+\varepsilon
\end{aligned} .
$$

The model of the credit union that has been presented is one of a monopoly. This is reasonable because of the nature of the common bond. However, the consequence is that the values of the decision variable elasticities are determined by local conditions given the population defined by the common bond. This is not the typical panel data problem where a common technology or preference structure is assumed. Because the optimal levels of the decision variables are a function of the unique distribution of income of the particular population served by the credit union, a separate test will be run for each case. There is no aggregation of results as even the random coefficients model has no role to play since there is no reason to presume that the parameters of each credit union should represent a random draw from a particular distribution. The results will thus be assessed in terms of the frequencies with which the restrictions are accepted or rejected. In addition there is no reason to assume that credit unions are homogeneous.

The first step is to estimate (16) and test $H_{0}: \alpha_{l}=\beta_{l}$; rejection of this identifies that the credit union is either operating under the intentional defaulter constraint or that it is active in the funds market. Ordinary least squares estimation of (16) reveals that autocorrelation is problem. The mean Durbin-Watson statistic for the loan (membership) regression is 1.540 (1.643) with a standard deviation of 0.411 (0.435). The 5\% critical values range from 0.595 to 2.339 and so are not reassuring. Consequently the variables were subjected to the Prais-Winsten transformation using the Durbin-Watson statistic as an estimate of the autocorrelation coefficient. The two 
equations were then estimated as a SUR system. Let $y_{i}, W_{i}, \mathrm{i}=L$ (oans), M(embers) be the transformed data matrices. $y_{i}$ is $20 \times 1$ and $W_{i}$ 20x7 (three macroeconomic variables, a dummy to distinguish which half of the year the observation was made in and three decision variables). The residuals from estimating the two equations by ordinary least squares were used to estimate $\Sigma$ the $2 \times 2$ covariance matrix of disturbances in any particular time period. Then if $Z=\left[\begin{array}{cc}W_{L} & 0 \\ 0 & W_{M}\end{array}\right]$ the covariance matrix, $C$, of the $(16 \times 1)$ vector of estimated parameters, $\hat{\gamma}$, is given by $Z^{\prime}\left(\hat{\Sigma}^{-1} \otimes I_{T}\right) Z$ where $\otimes$ indicates the Kronecker product and $I_{T}$ is a $20 \times 20$ identity matrix. To test the $\mathrm{k}$ linear restrictions $H_{0}: \quad R \gamma=r$ the Wald statistic, $(r-R \hat{\gamma})^{\prime}\left(R \hat{C} R^{\prime}\right)^{-1}(r-R \hat{\gamma})$, which is distributed as $\chi^{2}$ with $\mathrm{k}$ degrees of freedom, was employed (see Judge et al, 1980).

The next step involved testing that the macroeconomic and decision variables were simultaneously equal to zero and thus loans and membership fluctuated randomly about a constant mean in each half of the year. $\mathrm{H}$ was rejected for 608 out of the 666 unions; in order to determine the factors influential in this rejection the Wald statistic, $\mathrm{T}_{0}$, was regressed upon the macroeconomic variables and the characteristics of the union at the start of the period under investigation, together with their interactions. Variables that were insignificant were progressively dropped from the model. The result, presented below, is interpreted as a descriptive statistic.

$$
\begin{gathered}
T_{0}=6093-99.8 I N C-1415 U+71.7 U^{2}+16.5 I N C * U-0.0048 \text { AGECHART } \\
\begin{array}{cccc}
\text { (3.18) (2.32) (3.02) (2.84) (2.01) } & \text { (1.90) } \\
F=2.948[0.012] \quad & N=666
\end{array}
\end{gathered}
$$

(The figures in parentheses under the coefficients are the absolute $t$ ratios. The probability value of a test is given in square brackets. $N$ is sample size). The sign of 
the effect of a unit increase in INC is thus determined by the sign of $0.166 U-1$. Given that the mean state unemployment rate was $5.4 \%$ with a standard deviation of $1.2 \%$ the effect of an increase in INC would generally be positive except for those states with high unemployment. The sign of an unit increase in $U$ on the other hand depends on that of $0.102 U+0.012 I N C-1$; evaluated at the means this is -0.01 . Thus credit unions in states with higher than average unemployment are more likely to have their membership and total loans significantly related to their decision variables and state characteristics.

A charter number is assigned to each credit union on formation. If these are regressed on the age of the union a strong, downward sloping curve results. However, there are a number of mature unions with recent charter numbers. Such unions are the result of a merger or some form of change in designation. The variable AGECHART is the residual from the regression that will identify such unions. If a credit union merged during the test period then its membership would increase but without any apparent link to either the initial characteristics of the union or its macroeconomic environment. Thus the estimated coefficient would be anticipated to be negative as indeed is the case. ${ }^{8}$

Only the 608 unions that reject the hypothesis that the macroeconomic and decision variables were simultaneously equal to zero are included in the subsequent analysis. It was these unions that were tested for (11) and a significant role for market interest rates. The results are presented in the form of a contingency table (see Table 1). Equation (11) is not rejected for $362(60 \%)$ unions and $294(52 \%)$ fail to reject no relationship between the decision variables and the federal funds rate. The unions that reject (11) are made up of two distinct groups. Taking out those that have substantial

\footnotetext{
${ }^{8}$ For the 608 significant unions the mean of this variable is 51.4 ; for the remaining ones it is 539.0 .
} 
involvement in the funds market $(129,21 \%)$ leaves those that are subject to the intentional defaulter constraint $(117,19 \%)$. The descriptive statistics contained in Table 2 substantiate this interpretation.

The north west corner of Table 1, where (11) is rejected and no link with the federal funds rate is accepted, is highly distinctive. It is evident from Table 2 that the unions in this group are small in terms of assets, $\$ 2.23 \mathrm{~m}(\$ 5.84 \mathrm{~m})$ on average, where the figure in parentheses represents the 608 cases overall. This is reflected in the average share balance, $\$ 1130$ (\$1736). In terms of the other decision variables, this group has lower dividend rates, $2.04 \%(2.34 \%)$ and a higher loan rate at $12.73 \%$ $(12.21 \%)$

This group of credit unions, in the context of the model, faces the intentional defaulter constraint. Evidence of this is provided by the delinquency rate on loans (6.93\%) which is the highest of the four groups. The operation of the intentional defaulter constraint, equation (8), impacts on the levels of the decision variables. As can be seen from Table 2, the loan rate $(12.73 \%)$ is the highest of the four groups while the dividend rate $(2.04 \%)$ is the lowest. This in turn has implications for growth; membership growth is the lowest at $1.11 \%$ while that of loans is second lowest, standing at $3.16 \%$. Money market shares as a proportion of shareholder and depositor funds is lowest for this group (1\%) which suggests limited utilisation of wholesale funds by these credit unions. Intentional defaulters are those on the minimum income guarantee: the group under examination is based in states that on average have high unemployment rates (see Table 2). Intentional defaulters can be deterred from credit union membership by a high minimum deposit (c) or a low 
dividend rate $(t)$ : the evidence of the descriptive statistics is that the dividend rate is the principal instrument given that this is the lowest of the four groups at $2.04 \%$.

The 197 credit unions in the south west quadrant are similar to the previous group with respect to their delinquency rate $(6.38 \%)$ but appear to operate in a more favourable environment in that the income per capita is higher (and in fact is the highest of all four groups) and unemployment is lower. The absence of the operation of the intentional defaulter constraint leads to a reduced spread and a higher minimum balance. In terms of the growth of either membership or loans the two groups are alike; with respect to wholesale funds this group is marginally more active at $1.86 \%$.

Both the above groups are likely to make a contribution to welfare in distressed neighbourhoods, though that of the credit unions in the north west quadrant would be greater. The contrast between both these groups and the remainder is marked.

The north east quadrant of Table 1 consists of credit unions with characteristics that differ sharply with the two previous groups. These credit unions are larger with average assets of $\$ 8.47 \mathrm{~m}$ and an average share balance of $\$ 2,110$. As is evident from Table 2 the loan rate at $12.01 \%$ is the lowest of the four groups while the dividend rate $(2.49 \%)$ is the second highest. The relatively low loan rate together with pronounced activity in the money market encourages growth. These credit unions having the highest loan growth (4.77\%) and second highest growth of members $(1.35 \%)$.

The remaining group in the south east quadrant is broadly similar to the previous group in terms of average assets $(\$ 7.97 \mathrm{~m})$, average share balance $(\$ 2,090)$, loan and dividend rates respectively $12.04 \%$ and $2.65 \%$. The dividend rate is the highest of the four groups (the loan rate is second lowest) and they contribute, 
together with the most active money market involvement, to the high membership and loan growth. Both of the groups in the eastern half of the table would not be dissimilar to commercial banks and consequently would have limited relevance to distressed neighbourhoods.

The conclusion to the section on the model maintained that the operation of the intentional defaulter constraint would reduce the rate of growth of the credit union. Consequently in Table 3 the growth of both membership and loans is regressed upon personal income per worker, INC, and unemployment, $U$, as measures of the economic environment that the credit union operates in, and characteristics of the union as of the start of the sample period.

A consistent picture emerges from Table 3. Two points deserve to be highlighted. Income per worker is negative and significant in five out of the eight regressions. Total membership integrates the density between $x_{L}$ and $x_{U}$ (see footnote 5) where the latter gives the boundary above which commercial banks will replace credit unions as the primary financial intermediary. An increase in per capita income therefore reduces the proportion of the population for whom it is rational to join credit unions, explaining the negative estimated sign. In the case of credit unions that face the intentional defaulter constraint $(\mathrm{N}=117)$ income is not a significant factor in explaining growth; a general increase in income is unlikely to encourage many members of such institutions to transfer their custom to commercial banks.

One of the conclusions from the model (see point 5) was that the operation of the intentional defaulter constraint should reduce the rate of growth. This is borne out in Table 3 by the importance attributed to merger activity, as proxied by the variable AGECHART, in explaining the growth of such institutions. Moreover, a similar result 
holds for the other group which would be anticipated to operate in low income areas $(\mathrm{N}=197)$.

\section{Section 5 Concluding Comments}

The low-income credit union is modelled in this paper as an institution with a particular form of contract that is designed to allow it to operate among agents that are excluded from using banks due to the impact of informational asymmetries. Specifically credit unions deal with those potentially on the minimum income guarantee, the assumed alternative to accepting an income draw that results from a negative shock. The challenge facing them is to distinguish between those whose motivation is consumption smoothing and those who seek the largest credible loan with the intention of defaulting. This is achieved by setting the level of the minimum deposit and the loan and deposit rates such that an intentional defaulter has no incentive to join the credit union.

An important implication of the model is that the credit union may not be affected by changes in the market rate for funds; this is a consequence of its role as a provider of insurance services. Only if it is optimal for the credit union to borrow funds will its decision variables be influenced by the funds rate. The empirical analysis demonstrated that less than half of low-income credit unions were in this position.

If credit unions are to be an important agent in raising the welfare of distressed neighbourhoods then such an environment cannot be inimical to their growth. However, their success requires the screening out of the intentional defaulter and it is precisely this constraint that severely limits their potential. Even within the set of lowincome credit unions, only $19 \%$ fall into the above category. If the criterion is relaxed to include credit unions with similar characteristics to this group, namely that they are 
not significantly related to the funds market, then the proportion increases to just over one half $(52 \%)$. The potential of credit unions to address the problems of distressed neighbourhoods is depressingly revealed by the fact that low-income unions themselves constitute but $7 \%$ of the total. 


\section{References}

Akerlof, G., (1970), The Market for 'Lemons': Qualitative Uncertainty and the Market Mechanism, Quarterly Journal of Economics, Vol. 89, pp 488-500.

Basu, K., (1997), Analytical Development Economics: The Less Developed Economy Revisited, MIT Press, US.

Diamond, D., and Dybvig, P., (1983), Bank Runs, Deposit Insurance and Liquidity, Journal of political Economy, Vol. 91, pp 401-419.

Dymski, G., and Mohanty, L., (1999), Credit and Banking Structure: Asian and African-American Experience in Los Angeles, American Economic Association, Papers and Proceedings, pp 362-366.

Feinberg, R.M., (2001), The Competitive Role of Credit Unions in Small Local Financial Services Markets, The Review of Economics and Statistics, August, 83(3) pp 560-563.

Flowers, G., (1999), What Can We Expect From Community Based Lending for the District of Columbia, American Economic Association, Papers and Proceedings, pp 367-371.

Overstreet, G. and Rubin, G.M., (1990), Blurred Vision: Challenges in Credit Union Research Modelling, Filene Research Institute, Centre for Credit Union Research, 54 pages.

Parlour, C.A. and Rajan, U., (2001), Competition in Loan Contracts, American Economic Review, 91, pp. 1311-1328.

Smith, D.J., (1984), A Theoretic Framework of the Analysis of Credit Union Decision Making, The Journal of Finance, 39, 1155-1168.

Smith, D.J., (1986), A Test for Variant Objective Functions in Credit Unions, Applied Economics, 18, 959-970.

Srinivasan, A., and King; B., (1998), Credit Union Issues, Federal Reserve Bank of Atlanta, Third Quarter, pp. 32-41.

Tansey, C., (2001), Community Development Credit Unions: An Emerging Player in Low Income Communities, Capital Xchange, The Brookings Institute, 12 pages.

US Treasury, (1997), Credit Unions, US Government Printing Office. 
TABLE 1

CONTINGENCY TABLE OF HYPOTHESIS TESTS

\begin{tabular}{|c|c|c|c|c|c|}
\hline \multirow{4}{*}{$\boldsymbol{H}_{\boldsymbol{0}}: \eta_{\mathrm{s}}^{L}=\eta_{\mathrm{s}}^{M}$} & \multicolumn{3}{|c|}{$\mathrm{H}_{0}: \mathrm{s}$ related to $\rho$} & & \\
\hline & & Reject & Accept & & \\
\hline & Reject & 117 & 129 & 246 & $\mathrm{~T} 2$ \\
\hline & Accept & 197 & 165 & 362 & T3 \\
\hline & & 314 & 294 & 608 & \\
\hline & & $\mathrm{T} 1$ & $\mathrm{~T} 4$ & & \\
\hline
\end{tabular}

TABLE 2

DESCRIPTIVE STATISTICS

Reject ${ }_{\text {Ho }: \eta_{s}^{L}=\eta_{s}^{M}}^{\text {Accept }}$

$H_{0}: s$ related to $\rho$

\begin{tabular}{|l|c|c|c|c|c|c|}
\hline \multirow{2}{*}{$\begin{array}{l}\text { Variables } \\
\text { No. of Obs. }\end{array}$} & Accept & Reject & Accept & Reject & F & $\begin{array}{c}\text { Other } \\
\text { cases }\end{array}$ \\
\cline { 2 - 7 } & 165 & 197 & 129 & 117 & \\
\hline \multicolumn{7}{|c|}{ Decision Variables } \\
\hline Loan rate (\%) & 12.04 & 12.16 & 12.01 & 12.73 & $2.96[0.032]$ & 12.22 \\
\hline Div. rate (\%) & 2.65 & 2.16 & 2.49 & 2.04 & $9.65[0.000]$ & 2.46 \\
\hline Avshareb (\$,000) & 2.09 & 1.55 & 2.11 & 1.13 & $16.67[0.000]$ & 1.83 \\
\hline \multicolumn{7}{|c|}{ Characteristics } \\
\hline Assets (\$m) & 7.97 & 4.47 & 8.47 & 2.23 & $9.06[0.000]$ & 6.34 \\
\hline $\begin{array}{l}\text { Assets/Members } \\
\text { \$,000) }\end{array}$ & 2.35 & 1.76 & 2.36 & 1.30 & $15.91[0.000]$ & 2.07 \\
\hline $\begin{array}{l}\text { PROPOT } \\
\text { Money market } \\
\text { shares (\%) }\end{array}$ & 3.17 & 4.92 & 4.72 & 7.59 & $0.81[0.487]$ & 5.08 \\
\hline \multicolumn{7}{|c|}{ Performance } \\
\hline $\begin{array}{l}\text { Growth of } \\
\text { members (\% p.a.) }\end{array}$ & 1.64 & 1.18 & 1.35 & 1.11 & $1.26[0.286]$ & 1.26 \\
\hline $\begin{array}{l}\text { Growth of loans } \\
\text { \% p.a.) }\end{array}$ & 3.70 & 2.90 & 4.77 & 3.16 & $6.07[0.000]$ & 3.24 \\
\hline Deliquency (\%) & 3.52 & 6.38 & 4.44 & 6.93 & $5.78[0.001]$ & 3.74 \\
\hline \multicolumn{7}{|c|}{ Environment } \\
\hline $\begin{array}{l}\text { Income per } \\
\text { capita (\$,000) }\end{array}$ & 35.96 & 37.34 & 35.46 & 36.68 & $4.74[0.003]$ & 36.25 \\
\hline $\begin{array}{l}\text { Unemployment } \\
\text { \%) }\end{array}$ & 5.49 & 5.31 & 5.30 & 5.59 & $2.03[0.108]$ & 5.26 \\
\hline
\end{tabular}

1. PROPOT, the ratio of potential to actual members. 
TABLE 3

THE DETERMINANTS OF MEMBERSHIP AND LOAN GROWTH

\begin{tabular}{|l|l|l|l|l|l|l|l|l|}
\hline & \multicolumn{5}{|c|}{ Membership } & \multicolumn{3}{c|}{ Loans } \\
\hline $\mathrm{N}$ as in Table 1 & 165 & 197 & 129 & 117 & 165 & 197 & 129 & 117 \\
\hline Constant & 0.051 & 0.023 & 0.024 & 0.031 & 0.111 & 0.138 & 0.115 & 0.05 \\
& $(3.35)^{*}$ & $(3.54)^{*}$ & $(1.36)$ & $(4.80)^{*}$ & $(5.55)^{*}$ & $(5.08)^{*}$ & $(4.70)^{*}$ & $(4.31)^{*}$ \\
\hline INC & -0.753 & & -0.754 & & -1.517 & -2.241 & -1.905 & \\
& $(1.96)^{* *}$ & & $(1.91)^{* *}$ & & $(2.99)^{*}$ & $(3.41)^{*}$ & $(2.79)^{*}$ & \\
\hline$U$ & & & 0.003 & & & & & \\
& & & $(1.96)^{* *}$ & & & & & \\
\hline Age & -0.0003 & -0.0003 & & -0.0005 & -0.0006 & -0.0007 & & -0.0005 \\
& $(2.28)^{*}$ & $(1.70)^{* *}$ & & $(2.98)^{*}$ & $(3.05)^{*}$ & $(2.74)^{*}$ & & $(1.76)^{* *}$ \\
\hline Branches & 0.003 & & 0.007 & 0.008 & 0.005 & 0.007 & 0.009 & \\
& $(2.45)^{*}$ & & $(4.01)^{*}$ & $(1.78)^{* *}$ & $(3.16)^{*}$ & $(1.84)^{* *}$ & $(3.14)^{*}$ & \\
\hline Assets(\$m) & & & -0.0004 & -0.0038 & & & -0.0007 & \\
& & & $(1.89)^{* *}$ & $(3.13)^{*}$ & & & $(2.08)^{*}$ & \\
\hline Mem.(000's) & & & & -0.0098 & & & & \\
& & & & $(3.35)^{*}$ & & & & \\
\hline AGECHART(107) & & 3.624 & & 4.27 & & 6.231 & & 6.368 \\
& & $(2.78)^{*}$ & & $(3.83)^{*}$ & & $(3.00)^{*}$ & & $(3.114)^{*}$ \\
\hline PROPOT & 0.002 & & & & 0.0008 & & & \\
& $(5.461)^{*}$ & & & & $(2.09)^{*}$ & & & \\
\hline $\mathrm{R}^{2}$ & 0.213 & 0.044 & 0.164 & 0.225 & 0.147 & 0.146 & 0.112 & 0.084 \\
\hline F-statistic & 12.13 & 5.505 & 7.273 & 7.742 & 8.08 & 9.40 & 6.401 & 6.352 \\
& {$[0.000]$} & {$[0.005]$} & {$[0.000]$} & {$[0.000]$} & {$[0.000]$} & {$[0.000]$} & {$[0.000]$} & {$[0.000]$} \\
\hline
\end{tabular}

t-statistics are in parentheses - *significant at 5\%; **significant at $10 \%$ 
FIGURE 1

THE DEMAND FOR LOANS

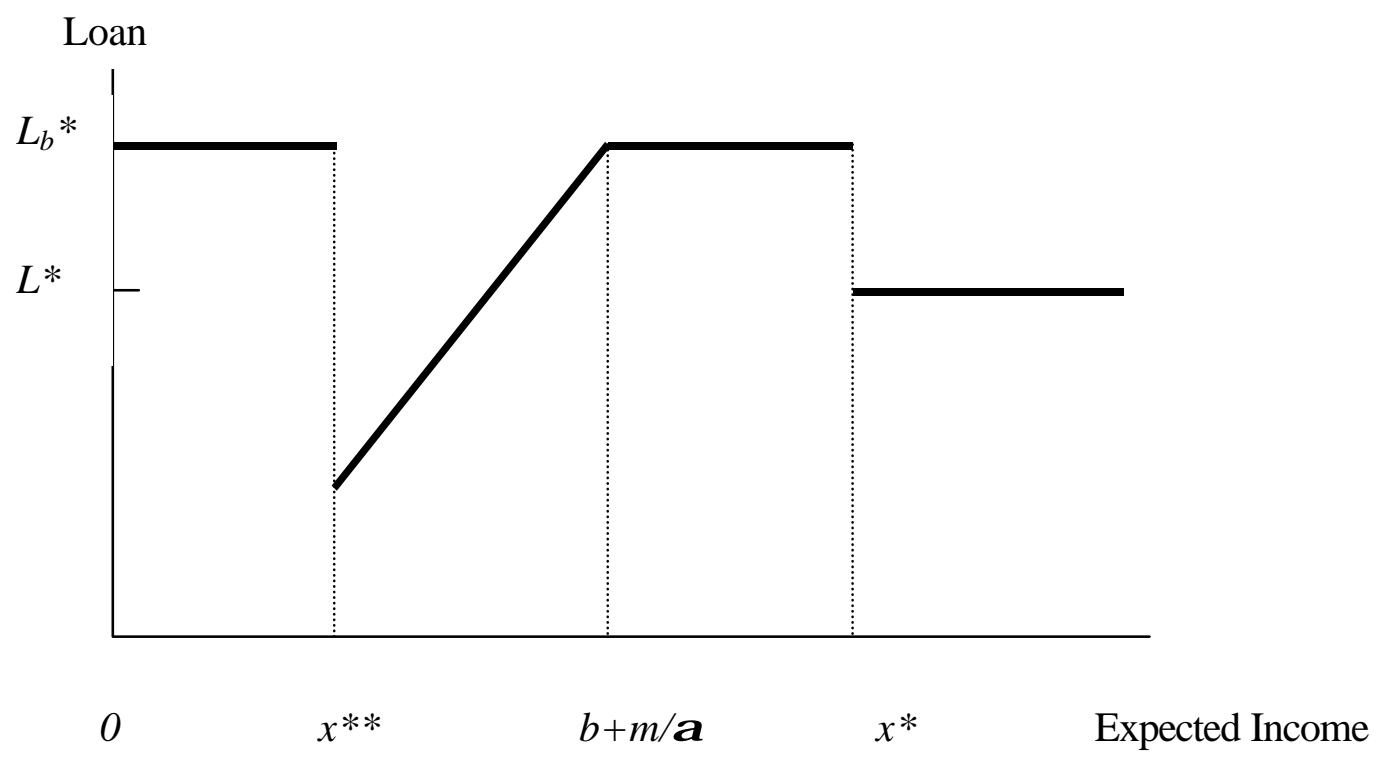


FIGURE 2

BENEFIT AND COST OF CREDIT UNION

MEMBERSHIP

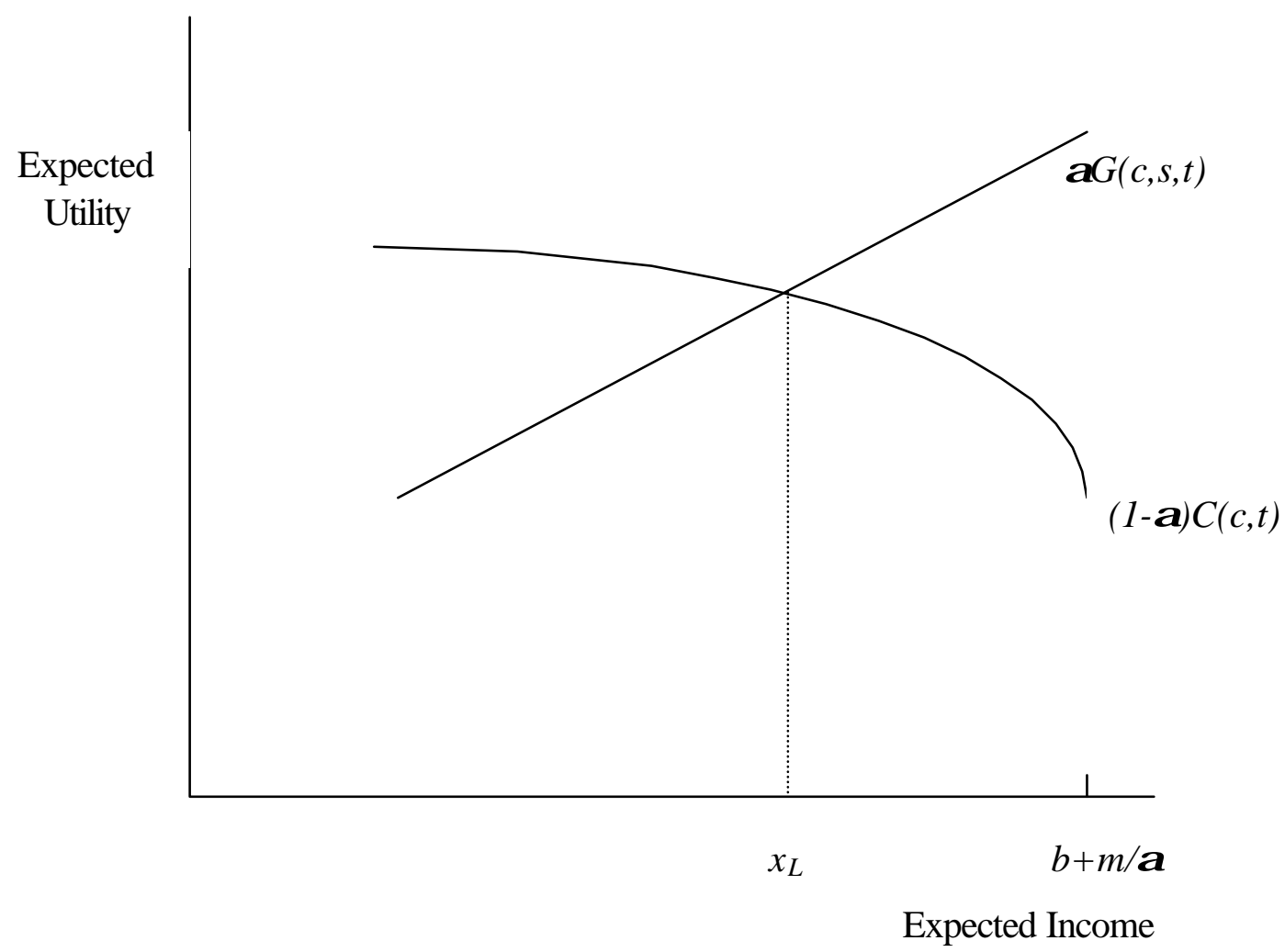




\section{FIGURE 3}

\section{SCREENING OUT THE INTENTIONAL DEFAULTER}

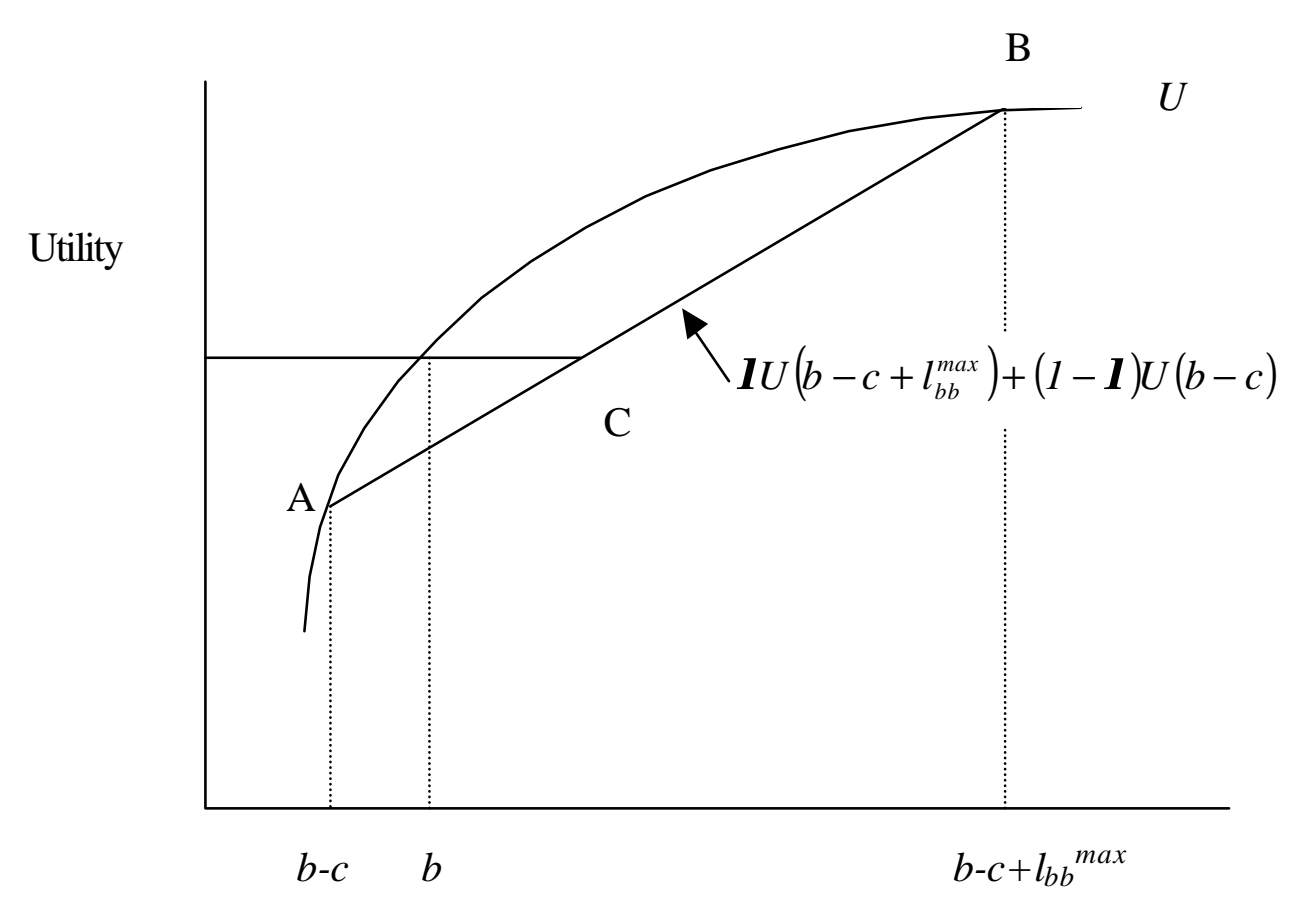

Consumption 